ORNL/TM-2015/190

CRADA/NFE-13-04816

\title{
Gas Turbine Heavy Hybrid Powertrain Variants: Opportunities and Potential for Systems Optimization
}

Approved for public release. Distribution is unlimited.
David Smith

Paul Chambon

July 2015 


\section{DOCUMENT AVAILABILITY}

Reports produced after January 1, 1996, are generally available free via US Department of Energy (DOE) SciTech Connect.

Website http://www.osti.gov/scitech/

Reports produced before January 1, 1996, may be purchased by members of the public from the following source:

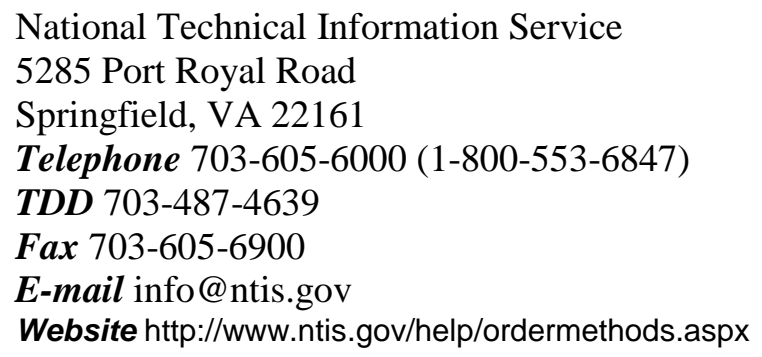

Reports are available to DOE employees, DOE contractors, Energy Technology Data Exchange representatives, and International Nuclear Information System representatives from the following source:

Office of Scientific and Technical Information

PO Box 62

Oak Ridge, TN 37831

Telephone 865-576-8401

Fax 865-576-5728

E-mail reports@osti.gov

Website http://www.osti.gov/contact.html

This report was prepared as an account of work sponsored by an agency of the United States Government. Neither the United States Government nor any agency thereof, nor any of their employees, makes any warranty, express or implied, or assumes any legal liability or responsibility for the accuracy, completeness, or usefulness of any information, apparatus, product, or process disclosed, or represents that its use would not infringe privately owned rights. Reference herein to any specific commercial product, process, or service by trade name, trademark, manufacturer, or otherwise, does not necessarily constitute or imply its endorsement, recommendation, or favoring by the United States Government or any agency thereof. The views and opinions of authors expressed herein do not necessarily state or reflect those of the United States Government or any agency thereof. 
ORNL/TM-2015/190

CRADA/NFE-13-04816

Energy \& Transportation Science Division

\title{
Gas Turbine Heavy Hybrid Powertrain Variants:
}

\section{Opportunities and Potential for Systems Optimization}

\author{
David Smith \\ Paul Chambon
}

Date Published: July 2015

\author{
Prepared by \\ OAK RIDGE NATIONAL LABORATORY \\ Oak Ridge, Tennessee 37831-6283 \\ managed by \\ UT-BATTELLE, LLC \\ for the \\ US DEPARTMENT OF ENERGY \\ under contract DE-AC05-00OR22725
}

Approved For Public Release 


\section{CONTENTS}

Page

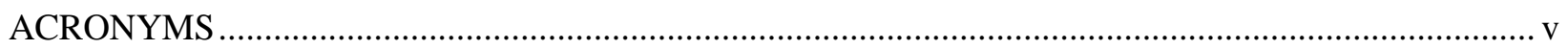

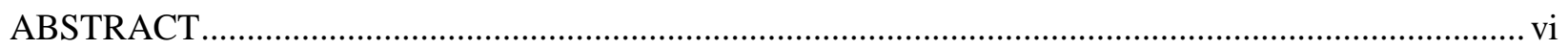

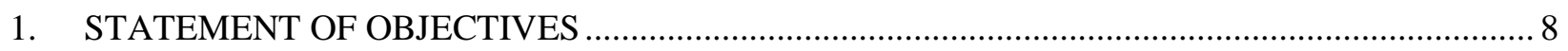

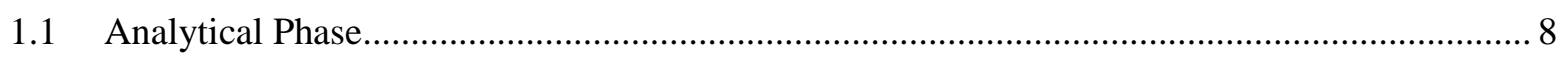

1.1.1 Development of detailed vehicle level models .......................................................... 8

1.1.2 Perform parametric simulations for PACCAR HEV equipped vehicle ........................ 9

1.1.3 Perform optimization of control strategy of the PACCAR Series HEV ....................... 9

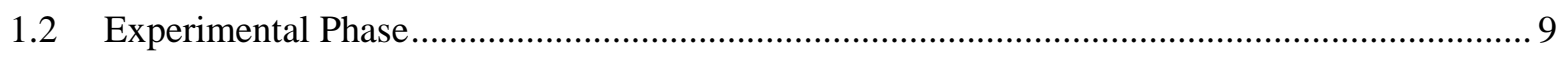

1.2.1 Integration of optimized Series HEV controls software into PACCAR

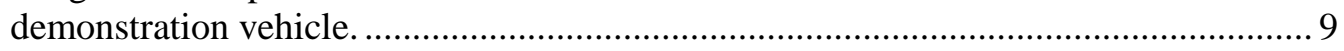

1.2.2 Performance evaluation of micro-turbine in HEV powertrain variants ....................... 9

2. BENEFITS TO THE DOE VEHICLE TECHNOLGIES OFFICE MISSION ................................. 12

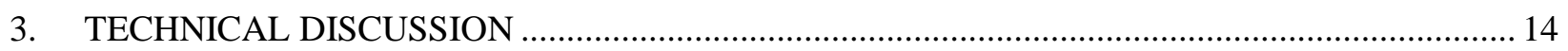

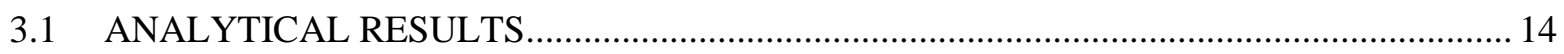

3.1.1 Development of detailed vehicle level models ....................................................... 14

3.1.2 Perform parametric simulations for PACCAR HEV equipped vehicle ....................... 14

3.1.3 Perform optimization of control strategy of the PACCAR Series HEV ...................... 14

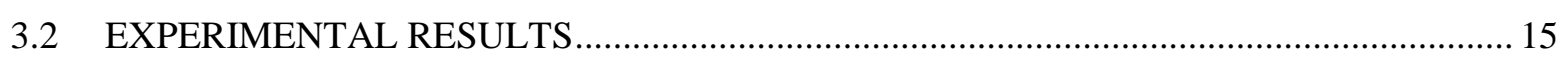

3.2.1 Integration of optimized Series HEV controls software into PACCAR

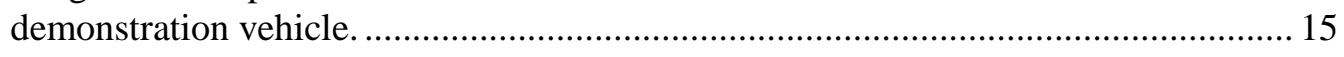

3.2.2 Performance evaluation of micro-turbine in HEV powertrain variants ....................... 15 


\section{ACRONYMS}

BSFC

CRADA

DOE

DC

HD

HEV

HTDC

MD

MTDC

ORNL

$R \& D$

SOC
Brake Specific Fuel Consumption

Cooperative Research and Development Agreement

U.S. Department of Energy

Direct Current

Heavy Duty

Hybrid Electric Vehicle

Heavy Truck Duty Cycle

Medium Duty

Medium Truck Duty Cycle

Oak Ridge National Laboratory

Research and Development

State of Charge 


\begin{abstract}
Widespread use of alternative hybrid powertrains is currently inevitable, and many opportunities for substantial progress remain. Hybrid electric vehicles (HEVs) have attracted considerable attention due to their potential to reduce petroleum consumption and greenhouse gas emissions in the transportation sector. This capability is mainly attributed to (a) the potential for downsizing the engine, (b) the potential for recovering energy during braking and thus recharging the energy storage unit, and (c) the ability to minimize the operation of the engine outside of its most efficient brake specific fuel consumption (BSFC) regime.

Hybridization of the Class 8, heavy-duty (HD) powertrain is inherently challenging due to the expected long-haul driving requirements and limited opportunities for regenerative braking. The objective of this project is to develop control strategies aiming at optimizing the operation of a Class $8 \mathrm{HEV}$ that features a micro-turbine as the heat engine. The micro-turbine application shows promise in fuel efficiency, even when compared to current diesel engines, and can meet regulated exhaust emissions levels with no exhaust after-treatment system. Both parallel and series HEV variants will be examined to understand the merits of each approach of the micro-turbine to MD advanced powertrain applications. These powertrain configurations enable new paradigms in operational efficiency, particularly in the Class 8 truck fleet. The successful development of these HEV variants will require a thorough technical understanding of the complex interactions between various energy sources and energy consumption components, for various operating modes.
\end{abstract}

PACCAR will be integrating the first generation of their series HEV powertrain with a Brayton Energy micro-turbine into a Class 8 HD truck tractor that has both regional haul and local pick-up and delivery (P\&D) components to its drive cycle. The vehicle will be deployed into fleet operation for a

demonstration period of six (6) months to assess real world operating benefits of the advanced powertrain. A parallel variant of the micro-turbine powertrain will be built and sent to the ORNL Vehicle Systems Integration Laboratory. 


\section{STATEMENT OF OBJECTIVES}

In order to assess the viability of the PACCAR micro-turbine series HEV and provide insight into supervisory controls optimization, a detailed vehicle system level model will be created. A target Class 8 heavy duty vehicle representative of a pick-up and delivery test mule will be jointly developed for the purposes of conventional powertrain comparisons to the PACCAR concept. The full vehicle model will be exercised utilizing duty cycle information mined from the ORNL Heavy Truck Duty Cycle (HTDC) database, as well as those provided by PACCAR. ORNL HTDC duty cycles will be developed based on real world test data collected from Class 8 line haul trucks that includes vehicle speed, grade information, and varying payloads. Based upon the results of this analytical phase and the success of the vehicle demonstration being conducted in parallel by PACCAR, an experimental phase may be embarked upon utilizing the demonstration vehicle and/or the ORNL Vehicle Systems Integration (VSI) Laboratory for detailed controls development/calibration and emissions validation.

\subsection{ANALYTICAL PHASE}

\subsubsection{Development of detailed vehicle level models}

The target vehicle for this study is based on the Fedex day cab tractor, with corresponding drag coefficient will be furnished by PACCAR, such as startability, gradeability, top speed, etc. Brayton will supply detailed micro-turbine data for heat engine to be modeled as part of this study. PACCAR will supply additional detailed powertrain/vehicle data as necessary to support the development of the following powertrain architectures:

a. Conventional powertrain. A conventional powertrain model will be developed to serve as a baseline for evaluating the merits of the PACCAR system. A basic control strategy must be developed for this vehicle in the form of transmission shift logic. Duty cycle data from the ORNL HTDC database will provide the necessary information for creating this algorithm.

b. PACCAR Micro-turbine Series Hybrid Powertrain. PACCAR will provide specific data for subsystem components, including performance specifications and system limitations. Brayton Energy will supply gas turbine specific performance data such that a representative plant model can be developed and used in the HEV models. A baseline supervisory control strategy will be developed based loosely upon the algorithms currently being utilized in the PACCAR demonstration vehicle. The supervisory control model will provide a basic architecture that allows effective coordination of subsystem components in a logical framework. ORNL and PACCAR will jointly develop the appropriate supervisory control architecture such that pertinent powertrain variables and system constraints are properly accounted for and available for successful development of the energy management algorithms.

c. PACCAR Micro-turbine Parallel Hybrid Powertrain. The vehicle level model developed in Part (b) above will be modified into a pre-transmission parallel hybrid electric vehicle. A baseline supervisory control strategy will be developed based upon current knowledge and experience with parallel HEVs with emphasis on HD applications. The supervisory control model will provide a basic architecture that allows effective coordination of subsystem components in a logical framework, similar to the series HEV approach. ORNL, Brayton, and possibly PACCAR will jointly develop the appropriate supervisory control architecture such that pertinent powertrain variables and system constraints are properly accounted for and available for successful development of the energy management algorithms. 


\subsubsection{Perform parametric simulations for PACCAR HEV equipped vehicle}

Each of the specific areas below will be simulated for both the conventional vehicle and PACCAR HEV cases such that an assessment of the benefits of the PACCAR HEV can be ascertained. The variables to be explored in this activity include:

a. Duty cycle and route profile. ORNL will utilize its HTDC database to derive pertinent duty cycles based upon real world operation of Class 8 long haul trucks. Three to five duty cycles (urban, highway/interstate, other TBD) will be generated that include vehicle speed data, grade information, and a range of payloads. In addition, PACCAR will provide their own pertinent duty cycles based upon previous experience and customer application.

b. Control strategies. PACCAR will provide the baseline demonstration vehicle control strategy to serve as a starting point for vehicle supervisory control development. Certain features of the control strategy will be parameterized in order to determine sensitivities to various approaches (charging profiles during series/parallel operation, micro-turbine start-stop frequency in conjunction with load following operation, micro-turbine response time characteristics, etc.).

\subsubsection{Perform optimization of control strategy of the PACCAR Series HEV.}

Results from Task 1.1.2 will be thoroughly analyzed with respect to component sizing, subsystem interactions, and general control algorithm effectiveness. The baseline control strategies developed in Task 2 will be optimized for fuel efficiency with respect to intended operational duty cycles.

a. Develop a control algorithm to identify online the optimal one-to-one correlation between the power required by the battery to maintain its state of charge (SOC) within a range of the target value and the current SOC for the self-sustainability of the vehicle.

b. Using a model representing the Class 8, series HEV with a micro-turbine engine, develop a control algorithm that will aim to optimize HEV operation for any different driving cycle, and demonstrate the effectiveness of its efficiency through simulation.

\subsection{EXPERIMENTAL PHASE}

\subsubsection{Integration of optimized Series HEV controls software into PACCAR demonstration vehicle.}

The resultant optimized control strategy will be integrated into the hardware of the demonstration vehicle for on-road evaluation and comparison to the baseline case. The testing will be conducted either during the fleet demonstration period or at PACCAR test facilities under more controlled conditions to understand the actual merit of the optimized strategies, and to evaluate the actual functionality of the micro-turbine operating under different modes. ORNL personnel will support PACCAR with the integration of the software models and provide limited on-site support during testing. A formal test plan will be developed as the project matures during the analytical phase.

\subsubsection{Performance evaluation of micro-turbine in HEV powertrain variants}

In cooperation with Brayton Energy and possibly PACCAR, a micro-turbine will be installed in the ORNL VSI Laboratory Powertrain Test Cell in order to establish the true merits of the powertrain, with emphasis on emissions. All pertinent powertrain and vehicle components will be emulated in real-time utilizing the VSI hardware-in-the-loop facility. Previously developed models can be targeted to real-time hardware quickly for evaluation of the operational characteristics of the micro-turbine, including start- 
stop characteristics and time response. Multiple fuels can be evaluated in the VSI facility, including natural gas, to evaluate the fuel efficiency merits and emissions performance. Due to the flexible nature of the VSI Laboratory, the micro-turbine can be subjected to a variety of vehicle weight classes and duty cycles to further understand the application of the micro-turbine to reducing petroleum consumption in the MD and HD sector.

a. Series HEV application. In addition to technical support, Brayton Energy will supply the microturbine/electric machine assembly that is capable of operating in both series and parallel configurations. For the series version, the ORNL VSI Battery Emulation System will be utilized to exercise the series genset. The optimized series HEV control algorithms developed earlier will be evaluated against an appropriate emulated vehicle for performance and emissions verification.

b. Parallel HEV application. The ORNL VSI Powertrain Test Cell features the capability to operate a full Class 8 powertrain (engine plus transmission), including use of the Battery Emulation System. The Brayton Energy micro-turbine will be connected to an existing 10 speed automated manual transmission currently in use in the ORNL VSI Lab. The Battery Emulation System will be utilized to supply DC power to the electric machine. The powertrain will then be subjected to a variety of vehicle classes and duty cycles in order to verify fuel economy and emissions performance. 


\section{BENEFITS TO THE DOE VEHICLE TECHNOLGIES OFFICE MISSION}

The Department of Energy (DOE) Vehicle Technologies Office (VTO) develops and deploys efficient and environmentally friendly highway transportation technologies that will enable America to use less petroleum. These technologies will provide Americans with greater freedom of mobility and energy security, while lowering costs and reducing impacts on the environment.

Hybrid powertrains are of considerable interest because of potential reductions in fuel consumption, criteria pollutants and greenhouse gas emissions. The proposed project will aim to optimize online the power management control of the Class 8, series HEV utilizing a CNG fueled micro-turbine engine operating over a variety of relevant duty cycles. It will allow for greater understanding of the applications of micro-turbines to HD advanced powertrain vehicles, particularly from an operational perspective. It will also increase the understanding of regional and local pick-up and delivery duty. Finally it will further the insight into the concept of fuel swapping, and the associated impacts of natural gas, diesel, and biodiesel fuels on efficiency and emissions. 


\section{TECHNICAL DISCUSSION}

\subsection{ANALYTICAL RESULTS}

\subsubsection{Development of detailed vehicle level models}

The simulation study was intended to compare a baseline conventional powertrain vehicle based on the FedEx day cab tractor with same vehicle platform equipped with a series and parallel hybrid powertrains comprised of Brayton's gas turbine engine and electric machine.

Brayton had created a theoretical physics-based model of their gas turbine for steady state operation implemented in Excel. PACCAR had implemented a Simulink model of the same gas turbine based on an efficiency table and first order dynamics.

The simulation study requires a dynamic Simulink model of the turbine in order to integrate it with the Autonomie vehicle model and subject it to transient vehicle drivecycles which would reflect the benefits of such a technology in real world conditions.

There is currently no complete experimental steady state mapping data for the turbine. Existing partial test data shows under-performing characteristics relative to theoretical expectations for that turbine. Also there is no transient test data at all.

The simulation study would be of limited value with theoretical data, therefore it was decided to wait on experimental data for the study to proceed.

Brayton built one prototype of their gas turbine generator. It is intended for integration in a PACCAR series hybrid powertrain vehicle. Developing the generator and truck monopolized all of Brayton and PACCAR resources such that generating steady state and dynamic data at this point for the simulation study is not an option. Moreover extracting mapping data from the vehicle will be difficult because the turbine engine is controlled to operate only at two different speed and loads, and transients are controlled to be very slow $(30-45 \mathrm{sec})$; so turbine engine dynamics cannot be investigated.

Therefore the simulation study had to be aborted.

\subsubsection{Perform parametric simulations for PACCAR HEV equipped vehicle}

The parametric study could not be completed because no reliable model was available for this task.

\subsubsection{Perform optimization of control strategy of the PACCAR Series HEV}

The control strategy optimization could not be completed because no reliable model was available for this task. 


\subsection{EXPERIMENTAL RESULTS}

\subsubsection{Integration of optimized Series HEV controls software into PACCAR demonstration vehicle.}

The optimization of Series HEV controls was intended to be performed on the PACCAR series HEV demonstration truck. That vehicle was still being worked on early March 2015 and was first scheduled for demonstration on a CEC project before it could be made available for this project. Also Brayton expected to perform an upgrade of their turbine after the CEC project is completed. That upgrade could take five to six months.

Bearing in mind the cost and resource constraints of both partners, that tentative plan could encounter more delays and is not guaranteed to succeed. Therefore the decision was made to cancel the CRADA.

\subsubsection{Performance evaluation of micro-turbine in HEV powertrain variants}

The CRADA was cancelled before the start of this task. 